\title{
An Innovative Management Perspective for Organizations through a Reputation Intelligence Management Model
}

\author{
Célia Maria Quitério Ramos, ESGHT, CIEO \& CEFAGE, University of Algarve, Faro, Portugal \\ Ana Maria Casado-Molina, University of Malaga, Málaga, Spain \\ José Ignácio-Peláez, University of Malaga, Málaga, Spain
}

\begin{abstract}
Banking companies aiming to maintain their sustainability in financial markets need to develop an integrated management based on the most important intangibles assets of relational capital. Decisionmakers need to analyze and understand a huge volume of opinions continuously generated in digital ecosystems about emotions and feelings that their stakeholders associate with the performance and communication of the brand. Current tools of management fail to consider transversal and holistic models, which study the frequency and value of existing relationships between the relational capital and intangible assets. In this research, an innovative management model based on reputation intelligence is proposed. This model incorporates methodology from business intelligence models, through OLAP and data mining techniques, to analyses the complex relationships among intangible assets experience, emotion and attitude. The proposed model was applied to companies in the banking sector and the results obtained permit a conclusion about the kinds of relationships for these intangibles in each bank.
\end{abstract}

\section{KEYWORDS}

Banking, Big Data, Business Intelligence, Corporate Reputation, Intangibles Management, Intangibles Models, Online Reputation, Sentiment Analysis

\section{INTRODUCTION}

In today's society, opinions about companies (Turban et al., 2017), their operational mode, and their products are continuously being commented upon in digital media, mainly in social media networks (Fuchs, 2017). The opinions that are expressed in digital ecosystems are related to experiences, emotions, and attitudes associated with brands and how firms communicate with consumers (Swani, Milne, Brown, Assaf, \& Donthu, 2017).

In the digital medium, it is possible to find tools to support the management process of tangible resources; however, intangible assets are not integrated, and their functionality is not contemplated by organizational management in an integral way (Dayan, Heisig, \& Matos, 2017).

At the same time, in social media, consumer opinions emerge with high frequency in the form of comments, which allow the evaluation of brands in order to perceive the relationships between the different tangible and intangible components of the business and their impact on companies' financial performance (Tuten \& Solomon, 2017).

To overcome this limitation, one of the possibilities is to integrate technology that automatically collects the opinions of consumers (Ramos et al., 2017a), to treat the data and analyze them with 
business intelligence tools that allow the company to obtain knowledge of the intangible resources of the company (Dayan et al., 2017).

The development of a model that incorporates the aforementioned functionalities and can be used according to a methodology that allows the emergence of intelligence as associated with the business will catapult the management of a company (Havakhor, Soror, \& Sabherwal, 2018) to a more efficient and effective level in order to achieve more demanding objectives and to compete in an increasingly observant and critical society.

The objective of this article is to present a model that incorporates business intelligence through the use of automated data collection and business intelligence tools aimed to obtain knowledge about organizational management through OLAP techniques and data mining methods; these can be used to treat, analyze, and visualize the relationships among the intangible components, mainly through the variables associated with the experience, emotion, and attitude of consumers. The proposed model can be applied to any economic sector; however, in the present study it was applied to the banking sector, where the results confirm that intangible assets have an impact on tangible ones, and vice versa.

The remainder of the article is divided into five sections. The first section will present the literature review and the intelligent model process. The second section will present the online reputational intelligence model, which includes the tangible and intangible resources of a company, defined by the variables of experiences, emotions, and attitudes. Results will be presented in the third section, taking into consideration OLAP and data-mining techniques. The fourth section will provide a discussion of this investigation, and the last section will present the conclusions.

\section{REPUTATION INTELLIGENCE MANAGEMENT MODEL}

In recent years, available information for businesses has gone from being scarce to very abundant. Data has become the new raw material for business, assuming a position almost as important as capital and labor. In business, more and more, information is a very relevant resource, since efficient management of information is fundamental for making strategic decisions (Laudon \& Laudon, 2017).

"Big data" offers a wide range of possibilities for organizations, but the five characteristics that define big data pose a number of problems that must be considered: volume, variety, velocity, veracity, and value (Chen \& Zhang, 2014).

A recent survey conducted by the Data Warehousing Institute (Halper, 2016), which analyzes big data of companies, shows that only $12 \%$ claim to have great success in its use; $64 \%$ report moderate success and 24\% report failure, as presented in Figure 1.

There are some reasons for organizations' failure to integrate big data in their information technology (IT) infrastructure: the complexity of the process of data source integration, poor data quality, the technological need to do data management in real time, lack of staff with the right skills, the wrong architectural definitions, and low available budget (Chen \& Zhang, 2014).

To overcome the problem in the processing and analysis of enormous volumes of data, the current technology brings solutions like Apache Hadoop (http://hadoop.apache.org) and the NoSQL DB (http://nosql-database.org), solutions that are low cost and which have the capacity to process terabytes of data in minutes or seconds. With regard to speed, generation, treatment, and analysis, solutions need to solve important challenges, especially regarding the quality of data treated in real time (Chen \& Zhang, 2014). As for the variety, the combination and integration of internal sources with external sources is one of big data's significant problems. Verification of quality is a difficult problem because data are not generated by the investigators, who are challenged by possible lack of data, noise, alterations, and other issues (Martins et al., 2015). Therefore, it is necessary to verify the quality of the data before and after the integration. Finally, there are problems related to the architecture: What type of NoSQL database will be used? What type of local cluster will be used, or will the cloud be used instead? 


\section{Big Data in the organizations}

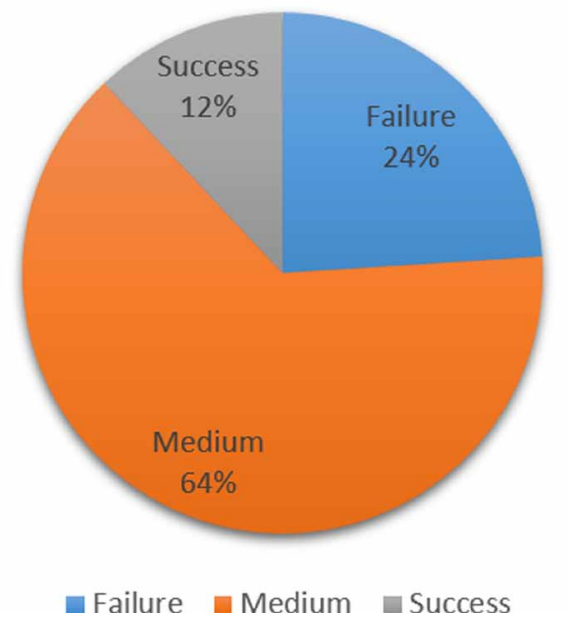

There are remarkable analytical possibilities for companies around big data (Gandomi \& Haider, 2015). At the corporate level, the main objective of data analysis is to improve strategic decisionmaking processes, thus improving business performance. It is at this point where a new term called business intelligence arises, which is the use of information and communication technologies for the improvement of strategic decision-making processes (Sharma, Mithas, \& Kankanhalli, 2014).

Traditionally, strategic decisions have been made through the proper analysis of available historical data; this allows firms to be able to analyze the causes of a current problem or situation, determine possible strategies, and predict the outcome of the firm's application (Ramos et al., 2017a).

The analytical possibilities of big data are enormous for all companies. Until now, the historical data used for analysis was internal data from transactional information systems (customer records, sales, purchases, employees) (Fuchs, Höpken, \& Lexhagen, 2014). But big data permits carrying out new types of analysis, with external data, for example, data generated in social networks. In this area, it is possible to carry out studies of different types: studies of reputation expressed in the digital environment, and studies of habits of connection, tastes, opinions, moods, quality management of services, security and surveillance, and design marketing campaigns (Gandomi \& Haider, 2015).

All companies are interested in controlling their reputation, but this is becoming extremely difficult. Due to rapid advances in digital technology, the reputation of brands is made available worldwide; customers' opinions about organizational strategies are expressed on social networks (Schwarz, 2012; Ramos, Casado-Molina, \& Peláez, 2017b) by interacting with other users of online communities ( $\mathrm{Li}, 2010$ ), sharing their experiences (Shapiro, 1983), voicing their opinions, and exerting their influence quickly and forcefully on a wider audience.

Consumer perception about brands should be taken into consideration to define new strategies (Casado, Méndiz, \& Peláez, 2013; Zink, 2005). In this context, it is possible for companies to look for favorable positioning in the reputation economy (Fecher, Friesike, Hebing, \& Linek, 2017) in order to obtain a sustainable difference and distinguish themselves in the competitive market $(\mathrm{Li}$, Sun, Chen, Fung, \& Wang, 2015; Millar, Hind, \& Maga, 2012).

Organizations are making significant effort to define models and tools to learn and understand their relationships with their different audiences. The reasons that justify the development of these models and tools stem from (1) the sustainability and contribution that intangible relational capital generates in business; and (2) companies' need to analyze massive collections of data extracted from 
digital ecosystems (e.g., social networks, forums, chatrooms) to measure the impact of stakeholder behaviors and extract predictions (Schermann et al., 2014).

There is an extensive literature on how to construct models to measure perceptions (Mehralian, Rasekh, \& Akhawan, 2013; Money, Rose, \& Hillenbrand, 2010) as well as on reputation management research (Highhouse, Brooks, \& Gregarus, 2009; Ponzi, Fombrun, \& Gardberg, 2011). However, only a few models have been implemented as tools in corporations.

The tools of intangible asset management are built on models that allow the monitoring of public perceptions of their relationship with the company, measuring the causes that justify this perception, and determining its impact on the company's intangible variables (Casado \& Pelaez, 2014). These tools provide ad hoc studies on relational capital intangibles, such as reputation, branding, and corporate social responsibility (CSR). Among the most important are the tool models RepTrak, TRI * M, and a tool offered by Alva.

RepTrak tool (Ponzi et al., 2011). This tool allows companies to diagnose perceptions of the general public, set goals, measure evolutionary change, and establish comparisons of the company's reputation with respect to the sector and by countries. In short, this tool allows companies to establish the correlation between reputation and attitudes or predisposition to the company.

TRI * M tool (O'Gorman \& Pirner, 2006). This tool allows the measurement and monitoring of relations with the company's strategic audiences, assessing the long-term trends between the different business units and establishing the strengths of relations with each of the stakeholder groups.

Alva tool (Alva, 2011). This tool measures the corporate reputation or perceptions of stakeholders in relation to the company, known at the time when various issues arise that affect the company in relation to the competition and its sector, either globally or by countries or regions.

Yet for all the models and tools used by large multinational firms, which offer annual evaluations, none contribute to a proactive and continuous management of the intangible corporate reputation, as currently required by the firms' boards (Casado \& Pelaez, 2014). They do not include crossmanagement of corporate reputation by departmental areas; the impact of public influencers on other stakeholders is not explained; and they do not determine the impact of stakeholder perceptions on global business and corporate areas. Of the models and tools discussed above, RepTrak is the only one that allows the option of diagnosing behaviors generated by these perceptions in public behavior. However, the collection of information is not daily; the tool is expensive; and it does not allow automation, treatment, and analysis of large volumes of information.

The Alva model adds different sources and is the only one that provides daily data, automating certain processes of gathering and processing information. However, it does not consider measurement by type of stakeholder, it does not allow quantification of the impact on the business, and it neither establishes holistic relationships between intangible and tangible assets nor their impacts through business intelligence models.

One of the limitations of these models is that they don't contemplate the transversal behavior of these intangible relational capital assets in relation to tangible values in business management, nor to how they have a holistic effect on the company as a whole and on different business areas (Shih-Ping, 2008).

In the present study, a reputation intelligence management model is considered to understand the contribution of a corporation's management that contributes to a holistic and transversal management of intangible assets and relational capital; the model is meant to be an innovative way of managing the resources of the organization with a view to overcoming the gap of not including intangible values in management models. To achieve this objective, the following hypotheses are proposed:

Hypothesis 1: The intangible relationships are transversal and holistic to the entire company.

Hypothesis 2: All the intangible assets have impacts among them (in all directions).

Hypothesis 3: An economic sector has different clusters of reputational performance. 


\section{Types of Intangible Resources in a Company}

Relational capital intangibles can be defined as the set of relationships that the enterprise maintains with its exterior or internal agents (Edvinsson \& Malone, 1997). Relational capital includes lived experiences of the public with brands, emotions that the environment and its different agents perceive about brands, and (3) favorable attitudes that generate loyalty to the brand. The concepts are considered in light of the type of public that has a relationship with the company.

\section{Experiences}

Experience with the brand has been studied not only by the perspective of "consumer experience" (Bolton, Gustafsson, McColl-Kennedy, Sirianni, \& Tse, 2014) but also by the experience of the reminder of the stakeholders (Davis, Buchanan-Oliver, \& Brodie, 2000). Depending on stakeholders' familiarity and interest in a specific theme based on their experience, the impact or social reaction will be more or less strong, and a favorable predisposition will or will not exist (Ijzerman, Janssen, $\&$ Coan, 2015). There are a great number of studies about the dimension of multiple stakeholders' experiences and main variables, which are very similar, highlighted in the work of Fombrun and Gardberg (2003) and Ponzi et al. (2011).

Experiences have an effect on the emotion of the consumer, and they can be associated with a product, the labor environment, ethics, social issues, the company's direction, and the profitability dimension. In this study, each kind of experience expressed in digital media is transformed into a range of 1-10, considering five categories, where values less than 2 represent an experience of "hate"; values greater than or equal to 2 and less than 4 represent an experience of "rejection"; values greater than or equal to 4 and less than 6 represent an experience of "indifference"; values greater than or equal to 6 and less than 8 represent an "acceptance" experience; and values greater than or equal to 8 represent an experience of "admiration".

\section{Emotions}

Scherer (2005) affirms that emotion is expressed through feelings and arises as a reaction to any situation or thing. Feelings summarize whatever is experienced and can convey the meaning of that experience, as feelings are the direct reaction to the individual's perception.

The study of Scherer (2005) includes the first instrument, which presents the dimensional place of emotions, called the Geneva Emotion Wheel. This is a tool for obtaining self-reports of emotional experiences with a goal to structure the exhaustive list of possible emotion names from free-format self-reports with minimal loss in expression capabilities.

In the present study, digital emotion is expressed in a valuation range of 1-10, following Miller's (1956) rating scale, which considers the polarity, intensity, and quality of the opinion expressed in this medium. Emotion is rated according to five categories, where value ranges and categories correspond to those mentioned above.

\section{Attitudes}

Attitudes are a set of beliefs or predispositions toward specific people or objects (Sherer, 2005), and they are associated with an intention and behavior (Ajzen \& Fishbein, 2005).

Attitude is a determinant characteristic but it neither expresses motivation to act nor has strength to activate it (Perugini \& Bagozzi, 2004). The behavioral intention is the direct determinant of the behavior - the mediator between attitude and conduct or behavior (Fombrun \& Gardberg, 2003).

Here the attitudes expressed in the technological medium use a range of $1-10$, defined by five categories, where the values near to 0 represent an attitude of "sell," values near to 2.5 represent an attitude of "keep/sell," values near to 5 represent an attitude of "neutral," values near to 7.5 represent an attitude of "hold/buy," and values near to 10 represent an attitude of "buy." 


\section{Relationship Between Intangible and Tangible Resources in a Company}

Jalonen (2014) states that brand owners should develop the ability to recognize shared emotions spread on social media, understanding their meaning to the business and behaving accordingly to that knowledge. Research has shown evidence not only for the relationships among intangible relational capital assets (experiences, emotions, and attitudes) but also for the relationship of those intangible assets with tangible or business assets of corporations.

Several studies support the relationship between intangible and tangible assets, and many authors consider the importance of working with appropriate tools which allow modeling precedents and effects of these actives on a dynamic, holistic, and transversal multidimensional construct (Lange, Lee, \& Dai, 2011; Millar et al., 2012; Wartick, 2002). The relationship between intangible and tangible resources can be expressed by the model shown in Figure 2, which presents all the dimensions considered by the experience: products, working environment, ethical behavior, social responsibility, direction, and profitability; an indicator to measure the emotion, in terms of polarity, intensity, and quality; the attitude defined by a recommendation that can contribute to define a behavior; and a business value expressed by tangible resources, such as stock market value.

Nevertheless, no evidence is found for a business intelligence model that allows establishing in a transversal and holistic way relationships between intangible relational capital assets (experiences, emotions, and attitudes) that the society has about a company as a consequence of the management of said enterprise and the impact generated on its business.

Therefore, a reputational intelligence management model is needed for construction and management of the brand within its activity context through which brand directors can detect and assess the daily opinions and expressed perceptions by the company's different stakeholders (Iglesias, Ind, \& Alfaro, 2013), and its impact on business both globally and transversally (by business areas).

\section{METHODOLOGY}

The process to define a reputation intelligent management model is constituted of five steps: data gathering, whereby the data are collected from the web; ETL (extract, transform, and load) to store the data, which include the data from internal and external sources; the data warehouse (DW), to store the data in a large database of the organization (Di Tria, Lefons, \& Tangorra, 2018; Ramos et al., 2017a); analysis of the data by means of OLAP and data-mining techniques; and the report management that includes indicators to analyze the business. This process is represented in Figure 3.

\section{Data Gathering}

Data gathering is divided into three steps: location, capture, and semantic analysis. Making an analysis and contextualizing these phases began with determining the sources of data and their characteristics.

Selecting a source of information can be complicated, due to the " $5 \mathrm{Vs}$ " that define big data: data volume, velocity of data collection, data variety, data veracity and data value (Di Tria, Lefons, \& Tangorra, 2013; IBM, 2017).

But before proceeding to the location phase, one needs to know the sources of the data, both internal and external. The data can be taken from social media, the internet of things, open data, and smart cities (Yang, Liu, Jia, Lin, \& Cheng, 2014).

For the location step, it is necessary to search for useful online data using the domain knowledge of the study, intuition, and automatic mechanisms. In this process it is necessary to not forget the concept Garbage In, Garbage Out (GIGO), i.e., the quality of a business intelligent application depends on the quality of the data introduced in it (Kim, Huang, \& Emery, 2016).

The data capturing step is made through known APIs, which will provide the data in different formats (Excel, XML, JSON, etc.) from external and internal sources, or through standard query languages. In addition, in the capture and storage step it will be necessary to guarantee the quality 
Figure 2. Relationship between intangible and tangible resources (author's elaboration)

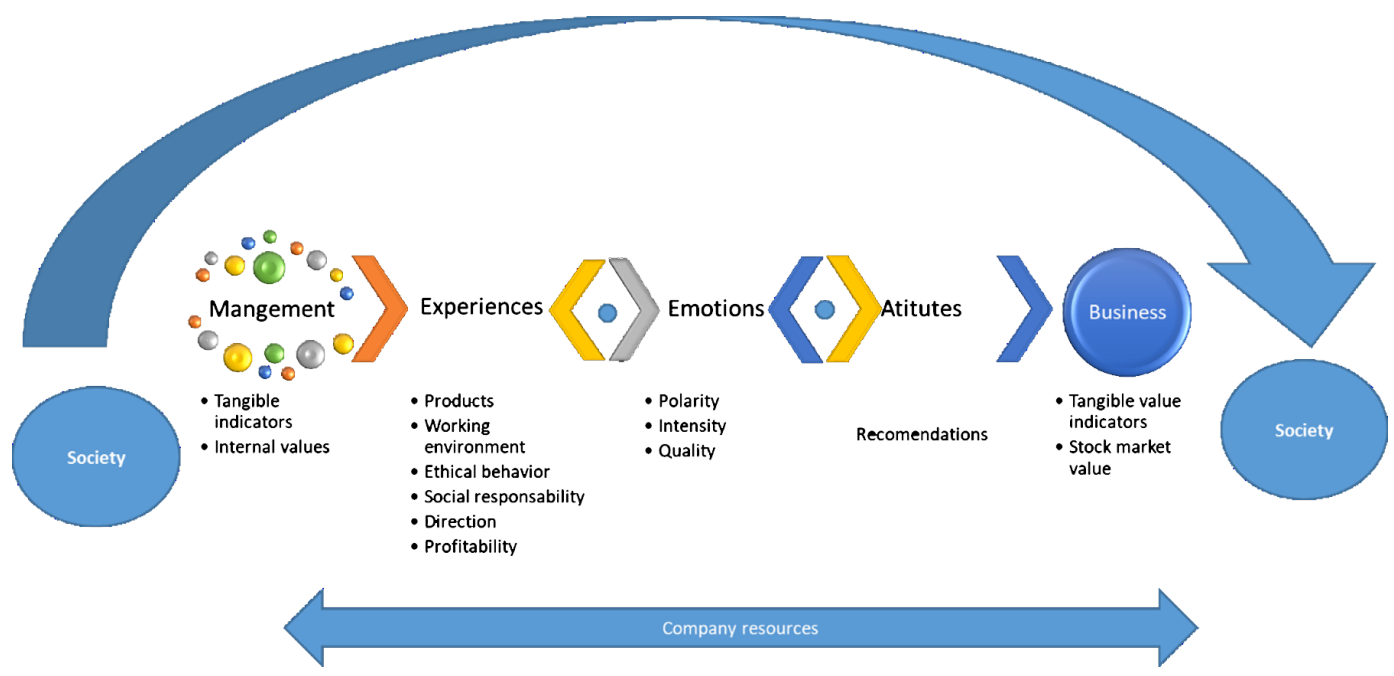

Figure 3. Reputation intelligent management model (Adapted from the INTED, 2016)

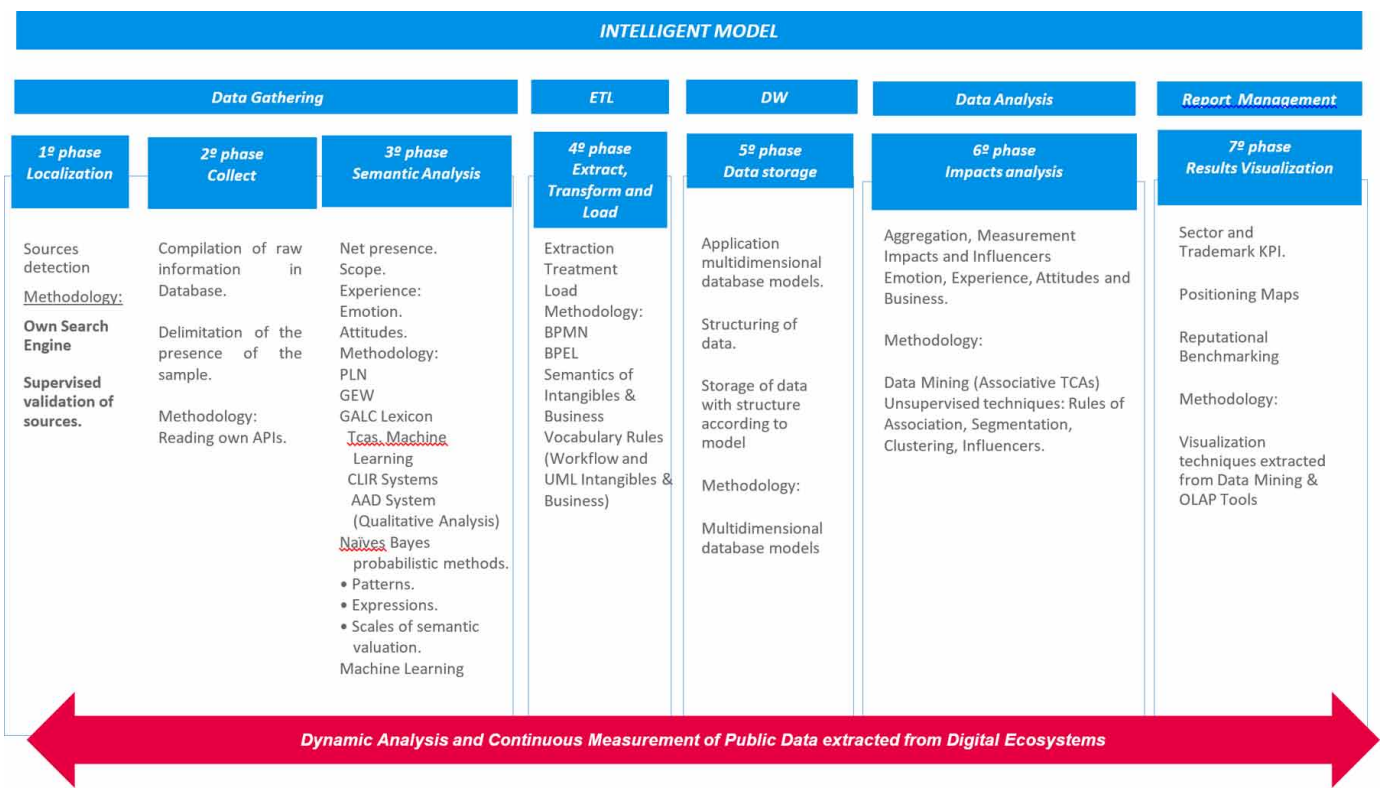

of the data used, for which it is necessary to carry out a process of cleaning, joining, diagnosing, pruning, filtering, and matching the data (Di Tria et al., 2013).

Once the sources are located and the information captured, a semantic analysis process must be carried out (in those data that need it). This process can be carried out using probabilistic techniques, based on Tresp (2000): naive Bayes, pattern-based techniques, or expression analysis. It can also be done through two types of supervised and unsupervised approaches (Neri \& Raffaelli, 2005).

The unsupervised approach is based on a list of words, so each one has been assigned a tone that can be positive, negative, or neutral. They have a success rate around $77 \%$. They usually work well 
for different themes and different languages (Pang \& Lee, 2008). The supervised methods require an initial set of texts whose tone has already been evaluated, for which manual correlation is done on the words that appear in those texts. They have a success rate of around $85 \%$. Their success depends a lot on the knowledge that the human evaluator has, and for each language and subject they need a specific training set.

\section{ETL the Data Gathered}

In the global process for the intelligent model considered in this study, for which data are gathered from several sources, the transformation of the data is not a linear process (Ramos, Correia, Rodrigues, Martins, \& Serra, 2015). Different sources have different structures and different meanings for the same organization's features (Martins et al., 2015).

To consolidate the extracted data, in order to ensure that the information is regular and consistent, it is necessary to define a set of guidelines for data conversion and also to include a set of several methodologies to do the conversion. These include business process management, business process execution language, semantics of intangibles, and business vocabulary rules.

\section{DW (Data Warehouse)}

A data warehouse (DW) is a database created to support the decision-making process, which is maintained autonomously and separate from the (transactional) organization's operational database.

The DW of the organization is a collection of integrated, non-volatile, and subject-oriented data, recorded over time, used to support the decision-making process (Inmon, 1996). All stored information is temporarily tagged and should allow storing data for several years (Santos \& Ramos, 2009).

Considering a data warehouse as a repository, it is necessary to follow a methodology for its construction (Caldeira, 2012). The architecture to be built could be a data warehouse (including the organization's global system) or a data mart (including an area or department of the organization) and should consider multidimensional modeling to define the structure of the repository (Santos \& Ramos, 2009).

\section{Data Analysis}

To explore a DW, it is necessary to deploy appropriate technology such as OLAP (On-Line Analytical Processing) and data-mining techniques (Santos \& Azevedo, 2005).

OLAP allows the creation of cubes to analyze information from different perspectives (dimensions). The cubes allow the analysis of facts available in the table of facts in the different dimensions considered in the modeling. Data-mining techniques contribute toward finding relationships, patterns, or models that are implicit in the data (Santos \& Ramos, 2009).

OLAP and data mining are powerful techniques; however, they present some drawbacks that are necessary to take into consideration to have a functional system (Cuzzocrea, Bellatreche, \& Song, 2013; Garrigós, Pardillo, Mazón, \& Trujillo, 2009; Prakash, \& Hanumanthappa, 2014). These include the following eight issues. (i) Data must be structured in a star or snowflake schema; these schemas are complicated to implement and maintain in one of these representation with the development of the business. (ii) Immediate data analysis is not possible without pre-modeling, which converts the data to a pattern in which the analyst can work directly. (iii) The decision maker is dependent on IT personnel; the personnel who intend to use OLAP and data mining have to work with IT staff because the elaboration of the queries among other SQL commands can be very complex. (iv) Powerful computation capability is needed to produce data analysis on a huge quantity of historical data. (v) Interactivity with the analysis results is not possible after the decision maker defines the step-by-step process to present the results; if it is necessary to change something, the analyst needs to start the process again. (vi) Data calculation is slow, even with powerful processing capability, and computer crashes can occur. (vii) Data representation in a cube is a good structure to analyze 
the data; however, for more than three dimensions it is difficult to represent the data in a way that facilitates the analyst's work. (viii) An OLAP system is independent from the transactional systems and it requires extra mechanisms (ETL) to access the data.

\section{Report Management}

Report management is constituted of regular presentation of information to managers within an organization to support them in the decision-making process. These reports can take the form of graphs, text, and tables, and are usually released through an intranet (or "enterprise portal") as a regularly updated set of web pages. Alternatively, they can be sent directly to employees or simply printed and distributed in the traditional way.

Another means to present the results is through a dashboard, which can show a range of indicators on a page and a set of goals for various metrics (Hill, 2017). The process of designing a reputation intelligence management model can be applied to different sectors, permitting the study of relationships among tangible and intangible resources. The intangible resources that will be considered are related to variables associated with the experience, emotion, and attitude that express the customers' opinions about the brand. In this context, the reputation intelligence management model can be the secret to administrate the brand intangibles in the digital environment efficiently, toward the aim of ensuring the organization's competitiveness.

\section{RESULTS OF THE APPLICATION OF THE REPUTATION INTELLIGENCE MANAGEMENT MODEL APPLIED TO THE BANKING SECTOR}

The proposed model was applied to the most relevant companies in the Spanish banking sector, considered in the IBEX35 stock market. The banking sector includes the seven most relevant corporations in Spain. Data sources from which opinions are extracted are the ecosystems that coexist in the digital environment, such as economic and financial sources (Stock Market Value Platform), hypertextual sources (mass media, online media, forums, websites), multimedia sources (YouTube), and social networks (Twitter and Facebook).

The study period was from January to December 2016. Data were extracted for all 365 days of the year; however, for some banks it was not possible to obtain data for the first day of the year, as was the case for the variable that measures attitude. To overcome this situation, all the days that had the value "not informed" were excluded from the analysis and therefore do not appear in the tables' information.

Taking into consideration the proposed hypotheses and the proposed model, the results provided are subdivided by OLAP and data-mining techniques.

\section{Results: OLAP Techniques}

To analyze the intangibles' relationships, we used OLAP techniques (Santos \& Azevedo, 2005). Figures 4, 5, and 6 show examples of these relationships measured in number of days. Each line presents the information associated with the opinion expressed in the digital medium for each specific day and for a particular bank.

For existing relationships between accumulated experiences in the category of emotion and attitude, it can be observed in Figure 4 that in bank \#5 there was a homogeneity in these relationships, as for 326 days the attitude remained neutral, direction experiences and emotion are of "hate." In banks \#1 and \#7, the attitude was concentrated in "buy/hold.". There are many days in which the direction experience category had a rank of acceptance or admiration and emotion had fewer days of acceptance or admiration. In bank \#1, it is interesting to note how 90 days with direction experiences and an emotion of indifference did not generate changes in the attitude toward buying.

It becomes evident that the category of direction experiences and the positive emotion on the rest of the days help to lower the probabilities of change in the perception of the analysts' recommendations. 
Figure 4. Relationship between the Experience of Direction, Emotion and Attitude (Author's elaboration) Legend: AT - Attitude, ED - Experience associated to the Direction of the company, EM - Emotion.

\begin{tabular}{|c|c|c|c|c|c|c|c|}
\hline Attitude (A) & & & Attitude (AT) & & & & \\
\hline Entity & - Direction Exp. & - Emotion (EM) - & AT Neutral & AT To Hold / Buy & AT To Keep / Sell & AT Uninformed & Total \\
\hline Bank \#1 & ED Acceptance & EM Acceptance & & 76 & & & 76 \\
\hline Bank \#1 & ED Acceptance & EM Indifference & & 35 & & & 35 \\
\hline Bank \#1 & ĐED Admiration & EM Acceptance & & 73 & & & 73 \\
\hline Bank \#1 & ED Admiration & EM Admiration & & 78 & & & 78 \\
\hline Bank \#1 & EDD Indifference & EM Indifference & & 90 & & & 90 \\
\hline Bank \#1 & $\bigoplus$ ED Reject & EM Indifference & & 6 & & 7 & 13 \\
\hline Bank \#2 & $\boxminus$ ED Acceptance & EM Acceptance & 14 & & & & 14 \\
\hline Bank \#2 & ED Acceptance & EM Indifference & 2 & & 70 & & 72 \\
\hline Bank \#2 & $\exists$ ED Admiration & EM Acceptance & 148 & & & & 148 \\
\hline Bank \#2 & ED Admiration & EM Admiration & 18 & & & & 18 \\
\hline Bank \#2 & E ED Indifference & EM Indifference & & & 55 & & 55 \\
\hline Bank \#2 & ED Indifference & EM Reject & & & 37 & & 37 \\
\hline Bank \#2 & $\boxminus$ ED Reject & EM Reject & & & 9 & 12 & 21 \\
\hline Bank \#3 & ED Acceptance & EM Acceptance & & & 60 & & 60 \\
\hline Bank \#3 & ED Acceptance & EM Indifference & & & 33 & & 33 \\
\hline Bank \#3 & EED Admiration & EM Acceptance & & & 67 & & 67 \\
\hline Bank \#3 & ED Admiration & EM Admiration & & & 67 & & 67 \\
\hline Bank \#3 & ED Indifference & EM Indifference & & & 70 & & 70 \\
\hline Bank \#3 & ED Indifference & EM Reject & & & 19 & & 19 \\
\hline Bank \#3 & $\boxminus$ ED Reject & EM Reject & 5 & & 36 & 8 & 49 \\
\hline Bank \#4 & $\boxminus$ ED Acceptance & EM Indifference & 155 & & & & 155 \\
\hline Bank \#4 & EED Indifference & EM Indifference & 30 & & & & 30 \\
\hline Bank \#4 & ED Indifference & EM Reject & 99 & 19 & & & 118 \\
\hline Bank \#4 & ED Reject & EM Reject & 17 & 37 & & 8 & 62 \\
\hline Bank \#5 & $\exists$ ED Hate & EM Hate & 326 & & & & 326 \\
\hline Bank \#5 & ĐED Reject & EM Hate & 31 & & & 8 & 39 \\
\hline Bank \#6 & EDD Acceptance & EM Indifference & 93 & & & & 93 \\
\hline Bank \#6 & EDD Admiration & EM Acceptance & 130 & & & & 130 \\
\hline Bank \#6 & ED Admiration & EM Indifference & 2 & & & & 2 \\
\hline Bank \#6 & ED Indifference & EM Indifference & 91 & & & & 91 \\
\hline Bank \#6 & ED Indifference & EM Reject & 9 & & & & 9 \\
\hline Bank \#6 & $\boxminus$ ED Reject & EM Reject & 21 & & & 19 & 40 \\
\hline Bank \#7 & $\boxminus$ ED Acceptance & EM Acceptance & & 132 & & & 132 \\
\hline Bank \#7 & ED Acceptance & EM Indifference & & 51 & & & 51 \\
\hline Bank \#7 & EDD Admiration & EM Acceptance & & 26 & & & 26 \\
\hline Bank \#7 & -ED Indifference & EM Indifference & 76 & 54 & & & 130 \\
\hline Bank \#7 & $\exists$ ED Reject & EM Indifference & 10 & & & & 10 \\
\hline Bank \#7 & ED Reject & EM Reject & 8 & & & 8 & 16 \\
\hline
\end{tabular}

In banks \#2 and \#3 we can observe that there is a heterogeneous behavior in the variables within a year. It has to be noted that the opinion of indifference and rejection on experience associated with the direction, which generated a negative or neutral emotion and concentrated the attitude of analysts mostly in selling. Therefore on most of the days their recommendation tended toward selling.

On existing homogeneous or heterogeneous relationships among these intangibles (see Figure 6), for example, bank \#5 had homogeneity in these relationships, as for 326 days the attitude remained neutral, and emotion and five of the six experience categories (products, profitability, social responsibility, direction, and labor environment) were of "hate" or "rejection." Otherwise, bank \#2 was very heterogeneous in its relationships; the attitude was concentrated in two ranks: "neutral" and "keep/sell" (see Figure 5). On one side, when the days with attitude were "neutral," all the emotions and the types of experience were positive; on the other side, when most of the time emotions were "rejection" or "indifference" the attitude was "keep/sell" but there was no homogenous valence or intensity with all the experiences. 
Figure 5. Relationships between Experiences, Emotion and Attitude (Bank \#2) (Author's elaboration) Legend: AT - Attitude, ED Experience associated to the Direction of the organization, EM - Emotion.

\begin{tabular}{|c|c|c|c|c|c|c|c|c|c|c|c|}
\hline \multirow[b]{2}{*}{ Entity } & \multirow[b]{2}{*}{ F. Products Exp. } & \multirow{2}{*}{ Faboral Exp. } & \multirow[b]{2}{*}{ Ethics Exp. } & \multirow[b]{2}{*}{ Focial Exp. } & \multirow[b]{2}{*}{ Direction Exp. } & \multicolumn{6}{|c|}{ Attitude $(A)$} \\
\hline & & & & & & Profitability Exp. & Femotion (EM) & AT Neutral & $\begin{array}{l}\text { AT To } \\
\text { / Sell }\end{array}$ & AT Uninformed & Total \\
\hline Bank \#2 & $\exists$ EP Accoptance & $\exists E L$ Indifference & $\exists$ EE Acceptance & $\exists$ ES Acceptance & e ED Acceptance & ER Acceptance & EM Acceptance & 14 & & & 14 \\
\hline Bank \#2 & EP Accoptance & EL Indifference & EE Acceptance & ES Acceptance & ED Acceptance & ER Acceptance & EM Indifference & 2 & 8 & 3 & 10 \\
\hline Bank \#2 & EP Acceptance & EL Indifference & EE Acceptance & ES Acceptance & ED Acceptance & $\exists$ ER Indifference & EM Indifference & & 10 & & 10 \\
\hline Bank \#2 & EP Accoptance & EL Indifference & EE Acceptance & ES Acceptance & EED Admiration & $\exists$ ER Acceptance & EM Acceptance & 7 & 7 & & \\
\hline Bank \#2 & EP Accoptance & EL Indifference & EE Acceptance & ES Indifference & e ED Acceptance & $\exists$ ER Indifference & EM Indifference & & 3 & 3 & 3 \\
\hline Bank \#2 & EP Accoptance & EL Indifference & $\exists$ EE Admiration & $\exists$ ES Acceptance & ED Acceptance & ER Acceptance & EM Indifference & & 12 & & 12 \\
\hline Bank \#2 & EP Accoptance & EL Indifference & EE Admiration & ES Acceptance & ED Acceptance & $\exists$ ER Indifference & EM Indifference & & 4 & 4 & 4 \\
\hline Bank \#2 & EP Accoptance & EL Indifference & EE Admiration & $\exists$ ES Indifference & e ED Acceptance & $\exists$ ER Indifference & EM Indifference & & 27 & & 27 \\
\hline Bank \#2 & $\exists$ EPP Admiration & JEL Acceptance & EE Acceptance & $\exists$ ES Acceptance & ED Admiration & ER Acceptance & EM Acceptance & 41 & & & 41 \\
\hline Bank \#2 & EP Admiration & EL Acceptance & EE Acceptance & ES Admiration & ED Admiration & $\exists$ ER Acceptance & EM Acceptance & 9 & & & \\
\hline Bank \#2 & EP Admiration & EL Acceptance & EE Acceptance & ES Admiration & ED Admiration & ER Admiration & EM Acceptance & 38 & & & 38 \\
\hline Bank \#2 & EP Admiration & ELL Admiration & EE Acceptance & ES Admiration & ED Admiration & ER Admiration & EM Acceptance & 52 & & & 52 \\
\hline Bank \#2 & EP Admiration & EL Admiration & EE Acceptance & ES Admiration & ED Admiration & ER Admiration & EM Admiration & 18 & & & 18 \\
\hline Bank \#2 & EP Admiration & $J E L$ Indifference & EE Acceptance & $\exists$ ES Acceptance & $\exists$ ED Admiration & $\exists$ ER Acceptance & EM Acceptance & 1 & 1 & & 1 \\
\hline Bank \#2 & JEP Indifforence & - JEL Indifference & EE Admiration & $\exists$ ES Indifference & ED Acceptance & ER Indifference & EM Indffference & & 6 & 5 & \\
\hline Bank \#2 & EP Indifference & EL Indifference & EE Admiration & ES Indifference & EED molfference & - $\exists$ ER Indifference & EM Indifference & & 19 & & 19 \\
\hline Bank \#2 & EP Indifference & - $\exists L$ Reject & EE Admiration & $\exists$ ES Indifference & E ED mdifference & - $\exists$ ER Indifference & EM Indifference & & 4 & 4 & 4 \\
\hline Bank \#2 & EP Indifference & EL Reject & EE Admiration & ES Indifference & ED indifference & - ERReject & EM Indifference & & 32 & & 32 \\
\hline Bank \#2 & EP Indifference & EL Reject & EE Admiration & ES Indifference & ED Indifference & ER Reject & EM Reject & & 7 & 7 & 7 \\
\hline Bank \#2 & EP Indifference & EL Reject & EE Admiration & ES Reject & $\exists$ ED Indifference & - $\quad$ ER Reject & EM Reject & & 15 & & 15 \\
\hline Bank \#2 & GEP Roject & JEL Hate & EE Admiration & $\exists$ ES Reject & $\exists$ ED Reject & $\exists$ ER Hate & EM Reject & & 5 & 12 & 17 \\
\hline Bank \#2 & EP Reject & $\exists$ EL Reject & EE Admiration & $\exists$ ES Reject & $\exists$ ED Indifference & - $\quad \exists$ ER Reject & EM Reject & & 15 & & 15 \\
\hline Bank \#2 & EP Reject & EL Reject & EE Admiration & ES Reject & ED Reject & ER Hate & EM Reject & & 4 & 4 & 4 \\
\hline
\end{tabular}

Figure 6. Relationships between Experiences, Emotion and Attitude (Bank \#5) (Author's elaboration) Legend: AT - Attitude, ED Experience associated to the Direction of the organization, EM - Emotion.

\begin{tabular}{|c|c|c|c|c|c|c|c|c|c|c|c|}
\hline \multirow[b]{2}{*}{ Entity } & \multirow[b]{2}{*}{ F Products Exp. } & \multirow[b]{2}{*}{ F Laboral Exp. } & \multirow[b]{2}{*}{ - Ethics Exp. } & \multirow[b]{2}{*}{ - Social Exp. } & \multirow[b]{2}{*}{ - Direction Exp. } & \multirow[b]{2}{*}{ - Profitability Exp. } & \multicolumn{5}{|c|}{ Attitude (AT) -} \\
\hline & & & & & & & - Emotion (EM) & - AT Neutral & & AT Uninformed & Total \\
\hline Bank \#5 & $\exists$ EP Hate & $\exists$ EL Hate & $\exists$ EE Acceptance & $\exists$ ES Reject & $\exists$ ED Hate & $\exists$ ER Hate & EM Hate & & 69 & & 69 \\
\hline Bank \#5 & EP Hate & EL Hate & $\exists$ EE Admiration & $\exists$ ES Hate & $\exists$ ED Rojoct & $\exists$ ER Hate & EM Hate & & 15 & & 15 \\
\hline Bank \#5 & EP Hate & EL Hate & EE Admiration & $\exists$ ES Reject & $\exists$ ED Hate & GER Hate & EM Hate & & 1 & & 1 \\
\hline Bank \#5 & EP Hate & EL Hate & EE Admiration & ES Reject & $\exists$ ED Reject & GER Hate & EM Hate & & 14 & & 14 \\
\hline Bank \#5 & EP Hate & EL Hate & $\exists$ EE Indifference & - $\quad \exists$ ES Reject & $\exists$ ED Hate & GER Hate & EM Hate & & 79 & & 79 \\
\hline Bank \#5 & EP Hate & EL Hate & $\exists$ EE Reject & $\exists$ ES Reject & $\exists$ ED Hate & GER Hate & EM Hate & & 28 & & 28 \\
\hline Bank \#5 & EP Hate & $\exists$ EL Indifference & $\exists$ EE Hate & $\exists$ ES Reject & $\exists$ ED Hate & GER Hate & EM Hate & & 11 & & 11 \\
\hline Bank \#5 & EP Hate & $\exists$ EL Reject & GEE Hate & $\exists$ ES Reject & ED Hate & JER Hate & EM Hate & & 35 & & 35 \\
\hline Bank \#5 & EP Hate & EL Reject & EE Hate & ES Reject & ED Hate & ERR Reject & EM Hate & & $\mathbf{1}$ & & 1 \\
\hline Bank \#5 & EP Hate & EL Reject & EE Reject & $\exists$ ES Reject & $\exists$ ED Hate & GER Hate & EM Hate & & 97 & & 97 \\
\hline Bank \#5 & $\checkmark$ EP Roject & EL Hate & EE Accoptance & - $\exists$ ES Reject & EED Hate & GER Hate & EM Hate & & 5 & & 5 \\
\hline Bank \#5 & EP Rojoct & EL Hate & EE Admiration & $\exists$ ES Hate & ED Reject & GER Hate & EM Hate & & & 8 & 8 \\
\hline Bank \#5 & EP Reject & EL Hate & EE Admiration & GES Reject & $\exists$ ED Reject & GER Hate & EM Hate & & 2 & & 2 \\
\hline
\end{tabular}

\section{Results: Data-Mining Technique}

To analyze whether all the intangible assets had impacts among them, we used data-mining techniques, which allowed the analysis of the key influencers from the whole sector (seven bank entities). The next figures show how all the variables influence each other transversally and holistically, as well as their impact value both from every category of experience to attitude and vice versa.

The key influencers are based on the naive Bayes algorithm, which can be used for prediction or for classification. The Bayes theorem can be used to calculate the probability of a hypothesis, taking into consideration given knowledge, expressed by the following equation (1):

$\mathrm{P}(\mathrm{hld})=(\mathrm{P}(\mathrm{dl} h) * \mathrm{P}(\mathrm{h})) / \mathrm{P}(\mathrm{d})$

where

$P(h \mid d)$ is the probability of hypothesis $h$ given the data $d$. This is called the posterior probability.

$P(d \mid h)$ is the probability of data $d$ given that hypothesis $h$ was true.

$P(h)$ is the probability of hypothesis $h$ being true (regardless of the data). This is called the prior

probability of $h$.

$P(d)$ is the probability of the data (regardless of the hypothesis). 
After the calculation it is possible to select or identify the hypothesis with the highest value, as presented in Table 1. The social experience with the value "indifference" had a $100 \%$ probability of having an emotion of "indifference" associated with it. An experience of profitability with the value of "acceptance" had a 100\% probability of having an emotion of "acceptance" associated with it.

Table 1 also shows that a "hate" experience associated with a product, a "hate" experience of direction, and a "hate" experience of profitability were highly probable of having an emotion of "hate" associated with them, $100 \%, 89 \%$, and $82 \%$, respectively.

Table 2 shows that a negative emotion of "hate" had an influence with a $100 \%$ probability in the analysts' recommendation attitude with the value "neutral". Table 2 shows that this behavior was perceived most of the days of the year in bank \#5 (see Figure 6) and, although in a lower number of days, in banks \#4 and \#7.

As can be observed in Table 3, there was a $100 \%$ influence from the "neutral" attitude toward an emotion with the value of "hate"; and the attitude of "hold/buy" favored an emotion with the value of "acceptance" with a probability of $100 \%$.

With regard to the emotion with the value of "admiration," as shown in Table 4, there was an influence in labor experience of "admiration" (100\%); however, an emotion of "hate" favored profitability, direction, product, and ethical experiences also with a "hate" value and an impact of $100 \%$.

Another analytic technique of this study considered the daily reputation of each bank using the k-means algorithm (Alsabti, Ranka, \& Singh, 1997) to delimit the different clusters of reputational performance in the banking sector. A clustering technique was applied to find situations with homogeneous relationships among intangible variables and define different heterogeneous groups of reputational situations in this sector.

In the k-means clustering algorithm (Alsabti et al., 1997; Jain, 2010), the number of clusters k is fixed and is applied to $\mathrm{n}$ observations, and the goal of K-means is to minimize the sum of squared error over all k clusters, defined by equation (2):

$$
\min \sum_{k=1}^{k} \sum_{x \in C_{k}}\left\|x_{i}-\mu_{k}\right\|^{2}
$$

Where $C_{k}$ is the set of $K$ clusters, $x_{i}$ is the set of observations to be clustered and $\mu_{k}$ the mean of cluster $C_{k}$.

Table 5 distinguishes five different reputational clusters. In this k-means $k=5$, once all the work considered the variables associated with experiences, emotion, and attitude classified in five

Table 1. Transversal Influence from Experiences on Emotion (Author's elaboration)

\begin{tabular}{|l|l|l|l|}
\hline \multicolumn{1}{|c|}{ Experience variable: } & \multicolumn{1}{c|}{ Value } & Favours an Emotion of & \multicolumn{1}{c|}{ Impact (\%) } \\
\hline Social responsibility & Indifference & Indifference & $100 \%$ \\
\hline Profitability & Acceptation & Acceptation & $100 \%$ \\
\hline Profitability & Admiration & Admiration & $100 \%$ \\
\hline Direction & Rejection & Rejection & $100 \%$ \\
\hline Product & Hate & Hate & $100 \%$ \\
\hline Direction & Hate & Hate & $89 \%$ \\
\hline Profitability & Hate & Hate & $82 \%$ \\
\hline
\end{tabular}


Table 2. Transversal Influence from Emotion on Attitude (Author's elaboration)

\begin{tabular}{|l|l|l|l|}
\hline \multicolumn{1}{|c|}{ Variable: } & \multicolumn{1}{|c|}{ Value } & \multicolumn{1}{|c|}{ Favours an Attitude of } & \multicolumn{1}{c|}{ Impact (\%) } \\
\hline Emotion & Hate & Hate & $100 \%$ \\
\hline
\end{tabular}

Table 3. Transversal Influence from Attitude on Emotion (Author's elaboration)

\begin{tabular}{|l|l|l|l|}
\hline \multicolumn{1}{|c|}{ Variable: } & \multicolumn{1}{c|}{ Value } & \multicolumn{1}{c|}{ Favours an Emotion of } & \multicolumn{1}{c|}{ Impact (\%) } \\
\hline Attitude & Hold/Buy & Acceptation & $100 \%$ \\
\hline Attitude & Neutral & Hate & $100 \%$ \\
\hline
\end{tabular}

categories, then the authors also considered it pertinent to create five clusters, where each cluster represented a reputation category.

As can be observed in Table 6, every cluster was distinguished by the value of direction experiences, expressed through the digital environment. The direction experiences appear in the first four groups where the values associated with these experiences and the rest of other situations define the heterogeneity of these clusters. In the last cluster, the main characteristic was the emotion of "hate," which influenced more than $70 \%$ of situations of products, direction, and profitability experiences. Therefore, the main variables to define the five clusters of the banking sector were direction experience and the emotion of "hate."

\section{DISCUSSION AND LEARNED LESSON}

Companies are incorporating tools that allow knowledge of the intangible relational capital assets (experiences, emotions, and attitudes of behavior that users form toward brands though digital ecosystems).

The intangible assets from digital ecosystems are one of the most important resources for organizations; however, there is a problem of how to manage the data associated with the big data concepts of the company. Nowadays, organizations need to apply tools to advance toward business intelligence models, incorporating automatization of information from digital sources, accumulation, daily data aggregation, and historic scenarios by brand, allowing visualization and analysis.

Although some available tools already incorporate automatization and daily online source aggregation, they do not quantify the impact of intangible assets within the organizations.

The tools associated with business intelligence models for the processing of big and complex volumes of information about intangible variables (experiences, emotions, and attitudes expressed through digital ecosystems) were OLAP and data mining, which allowed us to demonstrate that there are transversal and holistic relationships between both types of variables.

OLAP techniques allow us to know which behavior is the most frequent in the relationships among the different intangibles expressed on social media about different organizations. In the particular case of the banking sector, bank \#5 was the one with the most homogeneous behavior during the whole year; there was a concentration in the number of days where emotion and experiences by categories was always "rejection" and the attitude from the analysts was "neutral." However, in the case of bank \#2, there was a more heterogeneous behavior through the year, although there was a concentration in the "attitude" of "buy" from the financial analysts.

Through the application of the data-mining technique, using the key influencers and clustering, we detected that linear transversal relationships were recognized with an impact of $100 \%$ between intangibles; more specifically, the following relations were established: 
Table 4. Transversal Influence from Emotion into Experiences by categories (Author's elaboration)

\begin{tabular}{|c|c|c|c|}
\hline Variable: & Value & $\begin{array}{c}\text { Favours a Laboral } \\
\text { environment experience } \\
\text { of }\end{array}$ & Impact (\%) \\
\hline Emotion & Hate & Hate & $84 \%$ \\
\hline Emotion & Acceptation & Acceptation & $100 \%$ \\
\hline Emotion & Admiration & Admiration & $100 \%$ \\
\hline Variable: & Value & $\begin{array}{l}\text { Favours an ethics } \\
\text { experience of }\end{array}$ & Impact (\%) \\
\hline Emotion & Acceptation & Acceptation & $100 \%$ \\
\hline Emotion & Hate & Rejection & $100 \%$ \\
\hline Emotion & Hate & Hate & $100 \%$ \\
\hline Variable: & Value & $\begin{array}{l}\text { Favours a Profitability } \\
\text { experience of }\end{array}$ & Impact (\%) \\
\hline Emotion & Indifference & Indifference & $100 \%$ \\
\hline Emotion & Acceptation & Acceptation & $100 \%$ \\
\hline Emotion & Admiration & Admiration & $100 \%$ \\
\hline Emotion & Hate & Hate & $100 \%$ \\
\hline Variable: & Value & $\begin{array}{l}\text { Favours a Product } \\
\text { experience of }\end{array}$ & Impact (\%) \\
\hline Emotion & Rejection & Rejection & $91 \%$ \\
\hline Emotion & Admiration & Acceptation & $87 \%$ \\
\hline Emotion & Acceptation & Admiration & $100 \%$ \\
\hline Emotion & Hate & Hate & $100 \%$ \\
\hline Variable: & Value & $\begin{array}{l}\text { Favours a Social } \\
\text { Responsibility experience } \\
\text { of }\end{array}$ & Impact (\%) \\
\hline Emotion & Hate & Rejection & $100 \%$ \\
\hline Emotion & Indifference & Indifference & $100 \%$ \\
\hline Emotion & Acceptation & Acceptation & $100 \%$ \\
\hline Emotion & Acceptation & Admiration & $100 \%$ \\
\hline Emotion & Rejection & Hate & $100 \%$ \\
\hline Variable: & Value & $\begin{array}{l}\text { Favours a Direction } \\
\text { experience of }\end{array}$ & Impact (\%) \\
\hline Emotion & Rejection & Rejection & $100 \%$ \\
\hline Emotion & Indifference & Indifference & $90 \%$ \\
\hline Emotion & Indifference & Acceptation & $96 \%$ \\
\hline Emotion & Acceptation & Admiration & $100 \%$ \\
\hline Emotion & Hate & Hate & $100 \%$ \\
\hline
\end{tabular}

About relationships between emotion and attitude, the results were reciprocal: in $100 \%$ of the impacts, a hate emotion favored a neutral attitude and a neutral attitude favored a hate emotion. 
Table 5. Reputational Clusters of banking sector (Author's elaboration)

\begin{tabular}{|l|l|l|}
\hline \multicolumn{1}{|c|}{ Category Number: } & \multicolumn{1}{|c|}{ Category } & \multicolumn{1}{c|}{ Number of diary reputations } \\
\hline 1 & Direction Experience of Admiration & 606 \\
\hline 2 & Direction Experience of Acceptance & 779 \\
\hline 3 & Direction Experience of Indifference & 563 \\
\hline 4 & Direction Experience of Rejection & 242 \\
\hline 5 & Emotion of Hate & 365 \\
\hline
\end{tabular}

Table 6. Cluster profile of the banking sector (Author's elaboration)

\begin{tabular}{|c|c|c|c|}
\hline Cluster \#1: & Variable & Value & Relevance \\
\hline \multirow[t]{3}{*}{ Direction Experience of Admiration } & Direction experience & Admiration & $100 \%$ \\
\hline & Profitability experience & Admiration & $40 \%$ \\
\hline & Laboral experience & Acceptance & $32 \%$ \\
\hline Cluster \#2: & Variable & Value & Relevance \\
\hline \multirow[t]{3}{*}{ Direction Experience of Acceptance } & Direction experience & Acceptance & $100 \%$ \\
\hline & Laboral experience & Indifference & $61 \%$ \\
\hline & Profitability & Indifference & $51 \%$ \\
\hline Cluster \#3: & Variable & Value & Relevance \\
\hline \multirow[t]{3}{*}{ Direction Experience of Indifference } & Direction experience & Indifference & $100 \%$ \\
\hline & Profitability experience & Rejection & $56 \%$ \\
\hline & Laboral experience & Rejection & $45 \%$ \\
\hline Cluster \#4: & Variable & Value & Relevance \\
\hline \multirow[t]{3}{*}{ Direction Experience of Rejection } & Direction experience & Rejection & $100 \%$ \\
\hline & Product experience & Rejection & $80 \%$ \\
\hline & Laboral experience & Hate & $65 \%$ \\
\hline Cluster \#5: & Variable & Value & Relevance \\
\hline \multirow[t]{3}{*}{ Emotion of Hate } & Emotion & Hate & $100 \%$ \\
\hline & Product experience & Hate & $92 \%$ \\
\hline & Direction experience & Hate & $81 \%$ \\
\hline
\end{tabular}

On the relations between experience and emotion, the transversal influence from experience to emotion by categories had an impact of $100 \%$. This situation happens when experiences of products, direction, and profitability are ranked as hate, favoring an emotion of hate.

For bank \# 5, there was a homogeneity in its behavior that favors hate emotions and neutral attitudes, with impacts on the sectorial influence.

With the business intelligence tools, the three hypotheses for the banking sector were accepted: The intangible relationships are transversal and holistic (hypothesis 1). All the intangible assets have an impact between them (in all the directions) (hypothesis 2). In the banking sector, there are different clusters of reputational performance that permit the classification of the daily reputation for each bank, as presented by hypothesis 3 . 
In summary, the application of business intelligence techniques contributes to an innovative management in companies due to the treatment of a large daily volume of intangibles automatically extracted from opinions expressed in very diverse digital sources. Results can be incorporated in management reports or dashboards of the organizations.

The results of applying these techniques will help to maintain the market sustainability of the organizations and will permit them to advance toward the predictions of social behaviors to develop an innovated and anticipated management model for the companies.

\section{CONCLUSION}

In this work, an exhaustive background of the steps and techniques based on business intelligence models and the reputation management of the brand intangibles in the digital environment were conducted. OLAP and data-mining techniques were proposed for an innovative management model based on intangibles extracted from social media.

These techniques based on business intelligence permit the treatment, analysis, and visualization of complex relationships among intangible assets: experience, emotion, and attitude. This application to banking sector companies and the results obtained confirm which kinds of relationships have these intangibles in every bank and the impact on the reputation of the banking sector. In addition, the techniques permit the detection of the influence and impact of relationships that are both transversal and holistic (hypotheses 1 and 2).

Finally, using data-mining techniques, hypothesis 3 was verified, meaning that it is possible to define reputational clusters associated with banking sectors that permit the classification of each bank's reputation in a category, daily and throughout the year, to contribute toward managing the reputation intelligence associated with the organization, taking into consideration the tangible and intangible assets and the impact of the relationships among them.

In terms of future work, reputation analysis and management taking into account the concepts of business intelligence should incorporate metrics and methods that allow the development of a reputation indicator associated with the intelligence obtained by online reputation management, which will integrate the tangible and intangible assets of a company in an economic sector.

\section{ACKNOWLEDGMENT}

This research has been possible thanks to the financial support from the University of Málaga (Spain). We would also like to thank collaboration of the Chair of Metrics and Management of Intangibles of the University of Málaga and This paper is financed by National Funds provided by FCT - Foundation for Science and Technology through project CIEO (UID/SOC/04020/2019), project CEFAGE (UID/ ECO/04007/2019). 


\section{REFERENCES}

Ajzen, I., \& Fishbein, M. (2005). The influence of attitudes on behaviour. The Handbook of Attitudes, 173(221), 31 .

Alsabti, K., Ranka, S., \& Singh, V. (1997). An efficient k-means clustering algorithm. Electrical Engineering and Computer Science, 43.

Alva. (2011). The Alva methodology for corporate reputation analysis. London: Alva.

Bolton, R., Gustafsson, A., McColl-Kennedy, J., Sirianni, N., \& Tse, D. (2014). Small details that make big differences: A radical approach to consumption experience as a firm's differentiating strategy. Journal of Service Management, 25(2), 253-274. doi:10.1108/JOSM-01-2014-0034

Caldeira, C. (2012). Data Warehousing, Conceitos e Modelos (2ed.). Edições Sílabo: Lisboa.

Casado, A. M., Méndiz, A., \& Peláez, J. I. (2013). The evolution of Dircom: From communication manager to reputation strategist. Communicatio Socialis, 26, 47-66.

Casado, A. M., \& Peláez, J. I. (2014). Intangible management monitors and tools: Trends in the international companies. Expert Systems with Applications, 41(4), 1509-1529. doi:10.1016/j.eswa.2013.08.048

Chen, C. P., \& Zhang, C. Y. (2014). Data-intensive applications, challenges, techniques and technologies: A survey on big data. Information Sciences, 275, 314-347. doi:10.1016/j.ins.2014.01.015

Cuzzocrea, A., Bellatreche, L., \& Song, I. Y. (2013, October). Data warehousing and OLAP over big data: current challenges and future research directions. In Proceedings of the Sixteenth International Workshop on Data Warehousing and OLAP (pp. 67-70). ACM. doi:10.1145/2513190.2517828

Davis, R., Buchanan-Oliver, M., \& Brodie, R. J. (2000). Retail service branding in electronic-commerce environments. Journal of Service Research, 3(2), 178-186. doi:10.1177/109467050032006

Dayan, R., Heisig, P., \& Matos, F. (2017). Knowledge management as a factor for the formulation and implementation of organization strategy. Journal of Knowledge Management, 21(2), 308-329. doi:10.1108/ JKM-02-2016-0068

Di Tria, F., Lefons, E., \& Tangorra, F. (2014). Big data warehouse automatic design methodology. In Big Data Management, Technologies, and Applications (pp. 115-149). Hershey, PA: IGI Global. doi:10.4018/978-14666-4699-5.ch006

Di Tria, F., Lefons, E., \& Tangorra, F. (2018). A Proposal of Methodology for Designing Big Data Warehouses.

Edvinsson, L., \& Malone, M. (1997). Intellectual capital: Realizing your company's true value by finding its hidden brainpower. Nueva York: Harper Collins.

Fecher, B., Friesike, S., Hebing, M., \& Linek, S. (2017). A reputation economy: How individual reward considerations trump systemic arguments for open access to data. Palgrave Communications, $3,17051$. doi:10.1057/palcomms.2017.51

Fombrun, C. J., \& Gardberg, N. (2003). Who's tops in corporate reputation? Corporate Reputation Review, 3(1), 13-17. doi:10.1057/palgrave.crr.1540095

Fuchs, C. (2017). Social Media: A Critical Introduction. Sage (Atlanta, Ga.).

Fuchs, M., Höpken, W., \& Lexhagen, M. (2014). Big data analytics for knowledge generation in tourism destinations - a case from Sweden. Journal of Destination Marketing \& Management, 3(4), 198-209. doi:10.1016/j.jdmm.2014.08.002

Gandomi, A., \& Haider, M. (2015). Beyond the hype: Big data concepts, methods, and analytics. International Journal of Information Management, 35(2), 137-144. doi:10.1016/j.ijinfomgt.2014.10.007

Garrigós, I., Pardillo, J., Mazón, J. N., \& Trujillo, J. (2009, November). A conceptual modeling approach for OLAP personalization. In Proceedings of the International Conference on Conceptual Modeling (pp. 401-414). Springer. doi:10.1007/978-3-642-04840-1_30 
Halper, F. (2016). Best practices report | Data science and big data: Enterprise paths to success. The Data Warehousing Institute.

Havakhor, T., Soror, A. A., \& Sabherwal, R. (2018). Diffusion of knowledge in social media networks: Effects of reputation mechanisms and distribution of knowledge roles. Information Systems Journal, 28(1), 104-141. doi:10.1111/isj.12127

Helm, S. (2007). One reputation or many? Comparing stakeholders' perception of corporate reputation. Corporate Communications, 12(3), 238-254. doi:10.1108/13563280710776842

Highhouse, S., Brooks, M. E., \& Gregarus, G. (2009). An organizational impression management perspective on the formation of corporate reputations. Journal of Management, 35(6), 1481-1493. doi:10.1177/0149206309348788

Hill, G. (2017). A guide to enterprise reporting. Retrieved from http://ghill.customer.netspace.net.au/reporting/ definition.html

IBM. (2017). The 5 Vs of big data - Watson health perspectives. Retrieved from https://www.ibm.com/blogs/ watson-health/the-5-vs-of-big-data/

Iglesias, O., Ind, N., \& Alfaro, M. (2013). The organic view of the brand: A brand value co-creation model. Journal of Brand Management, 20(8), 670-688. doi:10.1057/bm.2013.8

Ijzerman, H., Janssen, J. A., \& Coan, J. A. (2015). Maintaining warm, trusting relationships with brands: Increased temperature perceptions after thinking of communal brands. PLoS One, 10(4), e0125194. doi:10.1371/journal. pone.0125194 PMID:25915686

Inmon, W. H. (1996). The data warehouse and data mining. Communications of the ACM, 39(11), 49-50. doi: $10.1145 / 240455.240470$

INTED. (2016). Cátedra de métricas y gestión de intangibles. II Informe de activos intangibles en ecosistemas digitales - 2016. Corporate Excellence.

Jain, A. K. (2010). Data clustering: 50 years beyond k-means. Pattern Recognition Letters, 31(8), 651-666. doi:10.1016/j.patrec.2009.09.011

Jalonen, H. (2014, September). Social media and emotions in organisational knowledge creation. In Proceedings of the 2014 Federated Conference on Computer Science and Information Systems (pp. 1371-1379). IEEE. doi:10.15439/2014F39

Kim, Y., Huang, J., \& Emery, S. (2016). Garbage in, garbage out: Data collection, quality assessment and reporting standards for social media data use in health research, infodemiology and digital disease detection. Journal of Medical Internet Research, 18(2), e41. doi:10.2196/jmir.4738 PMID:26920122

Lange, D., Lee, P. M., \& Dai, Y. (2011). Organizational reputation: A review. Journal of Management, 37(1), 153-184. doi:10.1177/0149206310390963

Laudon, K. C., \& Laudon, J. P. (2017). Management information systems: Managing the digital firm. Pearson.

Li, C. (2010). Groundswell. Winning in a world transformed by social technologies. Strategic Direction, 26(8).

Li, X., Sun, S. X., Chen, K., Fung, T., \& Wang, H. (2015). Design theory for market surveillance systems. Journal of Management Information Systems, 32(2), 278-313. doi:10.1080/07421222.2015.1063312

Martins, D., Ramos, C. M. Q., Rodrigues, J. M. F., Cardoso, P. J. S., Lam, R., \& Serra, F. (2015). Challenges in building a big data warehouse applied to the hotel business intelligence. In Proc. 6th Int. Conf. on Applied Informatics and Computing Theory (AICT'15), in Recent Research in Applied Informatics, (pp. 110-117). WSEAS.

Mehralian, G., Rasekh, H. R., \& Akhawan, P. (2013). Prioritization of intellectual capital indicators in knowledgebased industries: Evidence from pharmaceutical industry. International Journal of Information Management, 33(1), 209-216. doi:10.1016/j.ijinfomgt.2012.10.002

Millar, C., Hind, P., \& Maga, S. (2012). Sustainability and the need for change: Organizational change and transformational vision. Journal of Organizational Change Management, 12(25), 489-500. doi:10.1108/09534811211239272 
Miller, G. (1956). The magical number seven, plus or minus two. Psychological Review, 63(2), 81-97. doi:10.1037/h0043158 PMID:13310704

Money, K., Rose, S., \& Hillenbrand, C. (2010). The impact of the corporate identity mix on corporate reputation. Brand Management, 18(3), 197-211. doi:10.1057/bm.2010.31

Neri, F., \& Raffaelli, R. (2005). Text mining applied to multilingual corpora. In Knowledge Mining (pp. 123-131). Springer-Verlag; doi:10.1007/3-540-32394-5_9

O'Gorman, S., \& Pirner, P. (2006). Measuring and monitoring stakeholder relationships: Using TRI*M as an innovate tool for corporate communication. In M. Huber \& M. Pallas (Eds.), Customising Stakeholder Management Strategies (pp. 89-100). New York: Springer. doi:10.1007/3-540-31319-2_7

Pang, B., \& Lee, L. (2008). Opinion mining and sentiment analysis. Foundations and Trends in Information Retrieval, 2(1-2), 1-135. doi:10.1561/1500000011

Perugini, M., \& Bagozzi, R. P. (2004). The distinction between desires and intentions. European Journal of Social Psychology, 34(1), 69-84. doi:10.1002/ejsp.186

Ponzi, L. J., Fombrun, C. J., \& Gardberg, N. A. (2011). ReptrakTM pulse: Conceptualizing and validating a short-form measure of corporate reputation. Corporate Reputation Review, 14(1), 15-35. doi:10.1057/crr.2011.5

Prakash, B. R., \& Hanumanthappa, D. M. (2014). Issues and challenges in the era of big data mining. [IJETTCS]. International Journal of Emerging Trends \& Technology in Computer Science, 3(4), 321-325.

Ramos, C. M., Casado-Molina, A. M., \& Peláez, J. I. (2017b). Measuring air and terrestrial transport company reputation: Tourism intangibles expressed in the digital environment. Journal of Spatial and Organizational Dynamics, 5(4), 443-462.

Ramos, C. M. Q., Correia, M. B., Rodrigues, J. M. F., Martins, D., \& Serra, F. (2015). Big data warehouse framework for smart revenue management. In Proc. 3rd NAUN International Conference on Management, Marketing, Tourism, Retail, Finance and Computer Applications (MATREFC '15) (pp. 13-22). WSEAS.

Ramos, C. M. Q., Martins, D. J., Serra, F., Lam, R., Cardoso, P. J., Correia, M. B., \& Rodrigues, J. M. F. (2017a). Framework for a hospitality big data warehouse: The implementation of an efficient hospitality business intelligence system. International Journal of Information Systems in the Service Sector, 9(2), 27-45. doi:10.4018/IJISSS.2017040102

Santos, M., \& Azevedo, C. (2005). Data Mining. Lisboa: FCA Editora.

Santos, M., \& Ramos, I. (2009). Business Intelligence (2ed.). Lisboa: FCA Editora.

Scherer, K. R. (2005). What are emotions? And how can they be measured? Social Sciences Information. Information Sur les Sciences Sociales, 44(4), 695-729. doi:10.1177/0539018405058216

Schermann, M., Krcmar, H., Hemsen, H., Markl, V., Buchmüller, C., Bitter, T., \& Hoeren, T. (2014). Big data an interdisciplinary opportunity for information systems research. Business \& Information Systems Engineering, 6(5), 261-266. doi:10.1007/s12599-014-0345-1

Schwarz, A. (2012). Stakeholder attributions in crises: The effects of covariation information and attributional inferences on organizational reputation. International Journal of Strategic Communication, 6(2), 174-195. do $\mathrm{i}: 10.1080 / 1553118 X .2011 .596869$

Shapiro, C. (1983). Premiums for high quality products as returns to reputations. The Quarterly Journal of Economics, 98(4), 659-679. doi:10.2307/1881782

Sharma, R., Mithas, S., \& Kankanhalli, A. (2014). Transforming decision-making processes: A research agenda for understanding the impact of business analytics on organisations. European Journal of Information Systems, 23(4), 433-441. doi:10.1057/ejis.2014.17

Shih-Ping, J. (2008). Effects of corporate reputations, relationships and competing suppliers' marketing programmers on customers' cross buying intentions. Service Industries Journal, 28(1), 15-26. doi:10.1080/02642060701725370 
Swani, K., Milne, G. R., Brown, B. P., Assaf, A. G., \& Donthu, N. (2017). What messages to post? Evaluating the popularity of social media communications in business versus consumer markets. Industrial Marketing Management, 62, 77-87. doi:10.1016/j.indmarman.2016.07.006

Tresp, V. (2000). A Bayesian committee machine. Neural Computation, 12(11), 2719-2741. doi:10.1162/089976600300014908 PMID:11110133

Turban, E., Outland, J., King, D., Lee, J. K., Liang, T. P., \& Turban, D. C. (2017). Electronic Commerce 2018: A Managerial and Social Networks Perspective. Springer.

Tuten, T. L., \& Solomon, M. R. (2017). Social Media Marketing. Sage.

Wartick, S. (2002). Measuring corporate reputation. Definition and data. Business \& Society, 41(4), 371-392. doi:10.1177/0007650302238774

Yang, J., Liu, Z., Jia, C., Lin, K., \& Cheng, Z. (2014). New data publishing framework in the big data environments. In Proceedings of the 2014 Ninth International Conference on P2P, Parallel, Grid, Cloud and Internet Computing (pp. 363-366). IEEE. doi:10.1109/3PGCIC.2014.139

Zink, K. J. (2005). Stakeholder orientation and corporate social responsibility as a precondition for sustainability. Total Quality Management \& Business Excellence, 16(8-9), 1041-1052. doi:10.1080/14783360500163243

Célia M. Q. Ramos graduated in Computer Engineering from the University of Coimbra, obtained her master's in electrical and computer engineering from the Higher Technical Institute, Lisbon University, and the PhD in Econometrics in the University of the Algarve (UALG), Faculty of Economics, Portugal. She is Adjunct Professor at School for Management, Hospitality and Tourism, also in the UALG, where she lectures computer science. Areas of research and special interest include conception and development of information systems, tourism information systems, big data, etourism, econometric modeling and panel-data models. Célia Ramos has published in the fields of information systems and tourism, namely, she has authored a book, two book chapters, conference papers and journal articles. At the level of applied research, she has participated in several funded projects.

Ana María Casado-Molina earned her PhD degree from University of Málaga. She is a Professor of the Department of Economics and Business Administration, University of Málaga (Spain). Her line of research consists on corporate reputation, brand communication and intangibles management.

José Ignacio Peláez received the degree in Computer Sciences at the University of Granada and Ph.D, in computer Sciences at University of Granada in 2000. Currently, he is a professor at the University of Malaga, Department Languages and Computer Sciences, and Director of the Metric and Intagibles Management Chair. His areas of interest include intangibles, corporate reputation, consistency, aggregation operators, and business intelligent systems. Dr. Peláez has published more than 45 papers in refereed journals. 